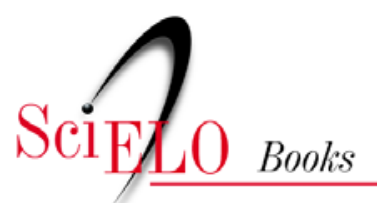

\title{
As múltiplas faces do médico-sanitarista
}

\author{
Soraya Almeida Belisário
}

\section{SciELO Books / SciELO Livros / SciELO Libros}

BELISÁRIO, S.A. As múltiplas faces do médico-sanitarista. In: MACHADO, M.H., org. Profissões de saúde: uma abordagem sociológica [online]. Rio de Janeiro: Editora FIOCRUZ, 1995, pp. 133-148. ISBN: 978-85-7541-607-5. Available from: doi: 10.7476/9788575416075.009. Also available in ePUB from: http://books.scielo.org/id/t4ksj/epub/machado-9788575416075.epub.

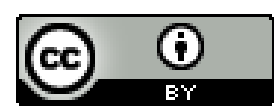

All the contents of this work, except where otherwise noted, is licensed under a Creative Commons Attribution $\underline{4.0 \text { International license. }}$

Todo o conteúdo deste trabalho, exceto quando houver ressalva, é publicado sob a licença Creative Commons Atribição 4.0.

Todo el contenido de esta obra, excepto donde se indique lo contrario, está bajo licencia de la licencia Creative Commons Reconocimento 4.0. 


\title{
As múltiplas faces do médico-sanitarista
}

\author{
Soraya Almeida Belisário
}

O objetivo deste texto é o estudo da metamorfose pela qual passou e passa a especialidade do médico-sanitarista desde sua constituição, buscando identificar os elementos que contribuíram para a sua progressiva descaracterização como uma especialidade médica.

\section{Médico-sanitarista, um especialista singular}

O médico-sanitarista sempre foi um especialista singular em relação a seus pares médicos. A despeito de ter, enquanto médico, cumprido todas as etapas do processo de profissionalização, ele incorpora, ao longo da evolução de sua especialidade, elementos que extrapolam os limites da profissão médica. São elementos que dizem respeito à natureza de seu objeto, ao corpo de conhecimentos necessário ao desenvolvimento de suas ações, à forma de trabalho e ao local em que esse trabalho se desenvolve.

Ao contrário dos demais especialistas médicos, o médico-sanitarista possui como objeto não o indivíduo, mas toda a população de uma determinada comunidade. Um objeto, portanto, de natureza essencialmente coletiva. Sua atividade se desenvolve no âmbito da saúde pública, ou, de forma mais abrangente, da saúde coletiva. Por isso a especialidade do médico-sanitarista incorpora em seu conteúdo programático a discussão interdisciplinar, lançando mão de um indispensável aporte de outras áreas do conhecimento, especialmente as ciências sociais.

Além de um conhecimento interdisciplinar, o desenvolvimento das ações do médico-sanitarista exige quase sempre a participação de profissionais de outras áreas, numa prática eminentemente coletiva e multiprofissional. Dessa forma, outros profissionais (enfermeiros, assistentes sociais, sociólogos, psicólogos, nutricionistas etc) atuam conjuntamente na saúde coletiva, uma área que, por suas características, não se apresenta 
como um território exclusivo de uma especialidade médica, mas como uma área de ampla atuação profissional. Assim, a idéia de cooperação, definida por Marx (1968) como a atuação simultânea de um grande numero de trabalhadores no mesmo local, ou se quiser, no mesmo campo de atividade..., pode ser utilizada para a caracterização da forma de trabalho do médico-sanitarista. Uma atividade intimamente ligada ao trabatho de outras categorias profissionais, numa ação cooperada, complementar, com vistas a um alvo comum - a população de uma determinada comunidade.

Por fim, como mais um elemento que caracteriza a singularidade do médico-sanitarista em relação aos demais especialistas médicos, está o local onde ele desenvolve suas atividades. $\mathrm{O}$ médico-sanitarista atua necessariamente em uma organização de saúde, enquanto os demais especialistas médicos possuem outras alternativas, como o atendimento em consultório.

Uma organização pode ser definida como um conjunto de padrões de interação humana, destinado a atingir metas específicas. Acrescente-se ainda que uma organização é um organismo vivo, adaptativo, que desenvolve seu próprio conjunto de suposições relativas a si mesmo e à sociedade mais ampla (Moraes, 1986). Assim, pode-se dizer que é nesse tipo de estrutura que o médico-sanitarista desenvolve sua ação. Uma estrutura que estabelece suas próprias normas, códigos e valores, impondo-os a todos que nela atuam.

Nas sociedades modernas, verifica-se que um número cada vez maior de profissionais trabalham em organizações. Profissionais assalariados, que desempenham suas atividades dentro de uma estrutura com hierarquia burocrática, em ocupações diversas. Embora esses profissionais conservem na maioria das vezes a referência básica de sua categoria profissional, eles se encontram submetidos a uma duplicidade de regras imposta por essa posição. O profissional é membro de duas instituições, a profissão e a organização; cada uma se esforça para controlar suas atividades ocupacionais; a profissão estabelece padrões e normas de conduta das atividades profissionais; a organização especifica tarefas objetivas $e$ controla a forma como essas são realizadas (Herries-Jenkins, s. d.).

O médico-sanitarista, a princípio e por princípio, incorpora-se a uma organização. Essa incorporação, no entanto, se dá de forma tão intensa que ele parece, de certa forma, perder a referência de sua categoria profissional. Além do mais, ele atua em organizações de saúde que são quase sempre de natureza pública e burocrática, outra característica pe- 
culiar dessa área. Essas organizações possuem particularidades que acabam por produzir efeitos tanto para a estrutura organizacional como para seus integrantes. Por serem públicas, têm como finalidade a prestação de serviços públicos. O caráter público do atendimento impede que a clientela seja selecionada e que esses serviços sejam remunerados. Além disso, dependem muito mais do ambiente sociopolítico, o que implica em uma instabilidade permanente.

Dessa forma, ser assalariado, trabalhar em organizações públicas e burocráticas de saúde, numa equipe multiprofissional, com um aporte de conhecimento interdisciplinar e possuir um objeto de natureza coletiva são características que fazem do médico-sanitarista um profissional diferenciado em sua corporação.

Ao se reconstituir a história do médico-sanitarista, observa-se que embora ele apresente, desde os primórdios de sua atuação, características peculiares em relação aos demais médicos, multiprofissionalidade e interdisciplinaridade são elementos que gradativamente foram se incorporando à especialidade, num processo social e historicamente determinado. Ao longo desse processo, o médico-sanitarista passou por diversas fases, que lhe imprimiram diferentes faces, cada uma apresentando características próprias. Observa-se também que a conformação de uma nova face não significou o desaparecimento da face anterior. O convívio entre elas se deu quase sempre de maneira pouco harmônica, identificando-se apenas a predominância de uma sobre a outra em determinados períodos.

\section{Um breve histórico das faces do médico-sanitarista}

A criação do Curso de Higiene e Saúde Pública para formar médicos-sanitaristas, em 1925, é o marco inicial do reconhecimento pelo Estado da atividade do sanitarismo como uma especialidade médica no Brasil. A discussão sobre a criação da especialidade do médico-sanitarista estava inserida no movimento de incorporação do paradigma da medicina científica desencadeado pela publicação do Relatório Flexner, que tinha entre seus elementos estruturais a especialização. Outro fator importante nesse processo foi a influência norte-americana exercida através de uma rede de agências liderada pela União Panamericana, posteriormente denominada Organização Panamericana de Saúde (OPS), que passou a investir, nos anos 20, na área de administração sanitária. Essa rede, denominada por Labra (1985) de conexão sanitária internacional, preconizava 
a responsabilidade do Estado pelos serviços nacionais de saúde, a coordenação desses serviços por médicos especializados em questões de higiene e saúde pública e a criação de Escolas de Saúde Pública e da carreira de sanitarista.

A especialização permitiria a aquisição de um estatuto formal pelas ciências sanitárias e a profissionalização, reconhecimento e permanência de médicos especializados na administração pública. A luta por sua criação era uma tentativa de demarcar mercado de trabalho, um mercado constituído fundamentalmente pelos serviços públicos de saúde, pelas instituições estatais. Já nesse momento, o médico-sanitarista se diferenciava dos demais médicos ao se reconhecer como assalariado, como membro de uma organização, ao propor a dedicação exclusiva à sua atividade e ao enfrentar os seus pares - os clínicos - na luta por um território profissional.

Sob a égide dos princípios da medicina científica, e conjugada à influência norte-americana, que preconizava uma nova postura em relação à higiene, às práticas em serviço e ao estudo da organização da saúde pública, conformou-se a primeira face do médico-sanitarista, denominada campanhista. Por sua atuação, marcada pela realização de pesquisas experimentais e de campanhas sanitárias voltadas para o controle de epidemias, a face campanhista do médico-sanitarista possuía como características mais importantes o biologicismo, o cientificismo e a atitude modernizadora.

A especialização tornou-se realidade, mas a criação de uma Escola de Saúde Pública, uma das reivindicações dos médicos-sanitaristas, não foi possível nesse momento. Eles, contudo, continuaram envidando esforços no sentido de manter a saúde pública como prioridade e reivindicando status na hierarquia política e administrativa. Esse status seria alcançado através da criação de um Ministério, o que só aconteceu com o irrompimento da nova ordem político-institucional instaurada pela Revolução de 30 .

O Ministério de Educação e Saúde foi criado em novembro de 1930, englobando o já existente Departamento Nacional de Saúde Pública (DNSP). Através da ação do DNSP, o Ministério constituiu-se em um orgão centralizador e interventor. Consolidou a prática do controle de endemias e epidemias, reforçando a face campanhista do médico-sanitarista, que, à semelhança da nova ordem política que se instituía, caracterizou-se pelo autoritarismo, intervencionismo e centralização.

O fim do Estado Novo e a instituição do regime populista confor- 
mou mais uma face do médico-sanitarista: a desenvolvimentista. Ela se esboçou nos anos 40, criticando o padrão a partir do qual a Saúde Pública vinha se estruturando e se antepondo filosófica e praticamente à face campanhista, e ganhou força a partir do desmembramento do Ministério da Educação e Saúde e da criação do Ministério da Saúde em 1953, quando um dos seus principais mentores, o Dr. Mário Magalhães da Silveira, passou a colaborar com os ministros da pasta até 1964. A partir dos desenvolvimentistas, os médicos-sanitaristas iniciaram seu afastamento do modelo médico tradicional, biologicista, centrado no combate às endemias e epidemias. Sua abordagem dos problemas de saúde enfocava a questão econômica como fonte geradora de doença, apontava a necessidade do planejamento setorial, retomava a medicina como ciência social, incorporando de maneira ainda tênue a questão social. Essa concepção seria aplicada nos cursos da Escola Nacional de Saúde Pública (ENSP), outra importante aspiração dos médicos-sanitaristas concretizada nessa época.

Contrariando antigas aspirações dos médicos-sanitaristas, a ENSP não se constituiu, no entanto, como um locus exclusivo de formação de especialistas médicos, mas como um espaço de formação de especialistas de diversas categorias profissionais. A estratégia de formação de sanitaristas adotada pela ENSP foi a de oferecer cursos de saúde pública para categorias específicas (médicos, enfermeiros, farmacêuticos, médicos-veterinários e engenheiros), além de cursos voltados para a formação de pessoal técnico. Os cursos ministrados pela ENSP vieram a consolidar uma proposta de formação de especialistas cuja meta era a preparação de técnicos e administradores de serviços de saúde. Começou a delinear-se, desde então, o caráter multiprofissional da saúde pública. A atividade do sanitarismo, até então desempenhada predominantemente por médicossanitaristas, passou a ser exercida por especialistas em saúde pública egressos de outras categorias profissionais. Já no final da década de 1960 assistiu-se à realização do Curso Básico de Saúde Pública, no qual diversas categorias profissionais passaram a compartilhar o mesmo espaço de formação.

A partir da segunda metade da década de 1960, a política de saúde adotada pelo Estado passou a privilegiar a atenção médica individual, de base hospitalar e privada, tratando com descaso as ações conduzidas pelo Ministério da Saúde. Observa-se, nesse momento, um retorno à face campanhista, que predominou sobre a desenvolvimentista, a despeito desta 
última ter obtido, no início da década, algumas conquistas em relação à condução das ações relativas à saúde pública.

Foi nesse período, fins dos anos 60 e início dos anos 70, que se deu uma intensa incorporação de inovações científicas e tecnológicas pela medicina, o que gerou profundas mudanças na prática e no saber médicos, levando à expansão das especialidades no Brasil. A divisão técnica do trabalho advinda dessas transformações impôs a segmentação da profissão médica e acentuou a complementariedade entre as diversas formas de trabalho (Donnangelo, 1975). Vê-se, nesse momento, reforçada a atipicidade da especialidade do médico-sanitarista em relação às demais especialidades médicas. À medida que o médico especialista legitimava-se social e culturalmente (Starr, 1992), tornando-se o protótipo da profissão, num movimento de valorização das especialidades, progressivamente o médico-sanitarista, assim como os demais profissionais sanitaristas, foise vendo alijado da condução e implementação das políticas de saúde.

O Ministério da Saúde, com seu discurso dominantemente campanhista e suas práticas rotinizadas e burocratizadas, sofreu um declínio progressivo. Com isso, também os sanitaristas viram-se relegados a um segundo plano, investidos de um papel secundário, residual, apenas mantenedor das antigas práticas campanhistas. Esse foi um período marcado pelo refluxo das ações de interesse coletivo e afluxo das ações individuais.

O período que vai de meados da década de 1970 ao início da década de 1980 é um período complexo e rico em transformações que são decisivas para a conformação de mais algumas faces do médico-sanitarista. Para uma melhor compreensão das mudanças pelas quais passou a especialidade nesse período é necessário fazer referência a duas vertentes teóricas difundidas na América Latina, a medicina preventiva e a medicina comunitária, que contribuíram para a formação de um novo pensamento e uma nova prática na área da saúde pública.

A medicina preventiva foi "um movimento ideológico que tinha como projeto a mudança da prática médica, através de um profissional médico que fosse imbuído de uma atitude formada nas Faculdades de Medicina e representou um leitura liberal e civil dos problemas do crescente custo da atenção médica (...) e uma proposta alternativa à intervenção estatal, mantendo a organização liberal da prática médica e o poder médico" (Arouca, 1975). O modelo preventivista, na sua redefinição das funções médicas, introduziu como elementos básicos o conceito ecológico de saúde e doença, a história natural das doenças e a multicausalidade. Criticou a prática médica vigente em suas características esta- 
belecidas pelo paradigma da medicina científica (o biologicismo, a especialização, a tecnificação e o seu caráter individualista) e utilizou como conceitos estratégicos a integração, a inculcação e a mudança. Delimitou sua ação entre os campos da saúde pública e da medicina social, estabelecendo uma ruptura com a higiene, se impôs como uma disciplina independente e aglutinou várias disciplinas, como a epidemiologia, as ciências sociais, a medicina quantitativa, a organização e administração sanitárias.

O discurso preventivista expandiu-se na América Latina através de uma estratégia empreendida por algumas fundações norte-americanas, em especial pela Organização Panamericana de Saúde (OPS). Fazia parte dessa estratégia a organização de seminários internacionais (Viña del Mar e Teochuacán). Esses seminários sugeriram, entre outras iniciativas, a criação dos Departamentos de Medicina Preventiva (DMP) nas escolas médicas. A absorção do modelo preventivista pelos DMP deu-se de forma diferenciada, observando-se contudo a predominância de um caráter racionalizador. Esse caráter racionalizador, aliado a uma visão de modernização, conformou a face racionalizadora/modernizante do médico-sanitarista.

O surgimento da face racionalizadora/modernizante aconteceu num momento de crise do modelo de assistência vigente, dentro de uma crise mais ampla pela qual passava o país. Contrapondo-se à conservadora face campanhista, a face racionalizadora/modernizante tentou resgatar para o Ministério da Saúde o papel de condutor das políticas de saúde. Embora ainda sob a influência do modelo médico, esta face incorporou idéias difundidas pela OPS, que orientavam para a execução de programas de medicina comunitária.

A medicina comunitária se originou nos Estados Unidos e se consolidou na América Latina, na década de 1970, através de programas de prestação de serviços a populações marginalizadas urbanas e rurais. Segundo Donnangelo (1979), “desenvolvendo-se na seqüência de outras propostas de recomposição da prática médica, tais como a Medicina Integral e a Medicina Preventiva, A Medicina Comunitária não se introduz como um novo campo conceitual frente a uma nova problemática, mas assenta em princípios já elaborados no interior daquelas propostas o seu projeto nuclear: uma estratégia de prestação de serviços à população". A medicina comunitária apresentou-se como um modelo mais racional ante a crescente demanda do setor saúde, incorporando temas das ciências sociais e da economia e preconizando a extensão de cobertura, a diminuição de custos, a simplificação tecnológica e a participação comunitá- 
ria. Sua proposta foi também denominada cuidados primários de saúde, atenção primária, medicina simplificada e programas de extensão de cobertura.

Também na década de 1970 , os DMP conduziram um processo de revisão do modelo preventivista que havia sido introduzido no ensino médico, criticando o modelo tradicional de formação de médicos e de sanitaristas. Como resultado dessa discussão, um novo corpo de idéias ganhou força dentro dos DMP, conferindo às ciências sociais um papel relevante na análise das condições e problemas de saúde da população. Um corpo de idéias que se constituiu em um novo marco conceitual da saúde pública - que passou, a partir daí, a ser denominada, mais amplamente, como saúde coletiva. Esse pensamento acenou com outras perspectivas de formação e atuação dos profissionais envolvidos no setor saúde. Perspectivas que foram efetivadas através de cursos de pós-graduação. Assim, entre outras experiências, destaca-se a criação do Curso de Medicina Social no Instituto de Medicina Social da Universidade do Estado do Rio de Janeiro. Para Nunes (1988), "essa pós-graduação, assim como o desenvolvimento das Residências em Medicina Preventiva e Social, no final de 70, e os Cursos de Especialização em Saúde Pública, como também os Cursos Regionalizados de Saúde Publica, a partir de 1975, representam um salto qualitativo da maior relevância para a área de $\mathrm{Me}$ dicina Social". Configurou-se assim mais uma etapa da metamorfose pela qual vinha passando o médico-sanitarista, conformando-se nesse momento a sua face médico-social. A face médico-social supera as antigas faces, afastando-se ainda mais do biológico e dirigindo-se para o social.

No decorrer desse processo, dois importantes acontecimentos devem ser destacados: a descentralização dos Cursos Básicos de Saúde Pública (CBSP) oferecidos pela ENSP e o desenvolvimento das Residências em Medicina Preventiva e Social (RMPS). A descentralização dos CBSP se deu no ano de 1975, compondo uma estratégia que visava a formação de uma massa crítica, através da aceleração da capacitação de profissionais. Essa estratégia levou a uma multiplicação sem precedentes na formação de sanitaristas, possibilitando a entrada maciça de outros profissionais na área da saúde pública. Objetivava-se, com isso, a formação de um generalista capaz de abordar as questões mais rotineiras em saúde pública. Conformou-se assim a face generalista do médico-sanitarista, agora irreversivelmente miscigenado a outras categorias profissionais. Além do aspecto quantitativo, a descentralização dos CBSP representou também uma mudança qualitativa, pela adoção de conteúdos inovadores. 
Quanto às RMPS, data de 1962 a criação do primeiro programa, na Faculdade de Medicina de Ribeirão Preto. Essa modalidade de formação, que se supunha ser uma via exclusiva do profissional médico, vem a algum tempo passando por um processo de revisão em que se discutem questões como a natureza e a especificidade do trabalho do profissional egresso desses programas e a não diferenciação desse profissional pelo mercado de trabalho.

\section{A face contemporânea do médico-sanitarista}

A VIII Conferência Nacional de Saúde, realizada em 1986, inaugurou uma nova era em relação ao desenvolvimento das políticas de saúde no Brasil. Suas propostas conduziram a um projeto de mudanças do sistema de saúde que culminou na idéia de uma ampla Reforma Sanitária. Uma reforma que repercutiria nos planos político, jurídico e institucional, apresentando-se como uma alternativa à então vigente organização do sistema de saúde.

Segundo Teixeira, "a construção do projeto da reforma sanitária funda-se na noção de crise: crise do conhecimento e da prática médica, crise do autoritarismo, crise do estado sanitário da população, crise do sistema de prestação dos serviços de saúde. Assim, a estratégia de transformação da situação de crise, inspirada em uma leitura socializante da problemática da saúde, concretiza-se na perspectiva da luta pela democratização que se baseia na interpelação dos indivíduos enquanto cidadãos, capazes de aprofundar sua consciência sanitária, e assim transformarem-se em atores sociais organizados na luta pelo direito à saúde como dever do Estado" (Teixeira, 1988).

O processo de Reforma Sanitária funcionaria como uma alavanca na luta pelo Sistema Único de Saúde (SUS), no sentido de resgatar a qualidade e a credibilidade dos serviços públicos. Nesse momento, em que se tentava trazer a questão sanitária para o centro da cena, viu-se novamente politizada a questão da saúde. Com a proposta da Reforma Sanitária, "surge na cena política brasileira a noção de direito social universal, entendido como atributo de cidadania sem qualificações, ao qual deve corresponder, como direito, não como concessão, uma ação estatal constitutiva da oferta de serviços que lhe são inerentes" (Favaret \& Oliveira, 1990).

Como parte desse projeto, discutiu-se a necessidade de uma reorientação da política de desenvolvimento de recursos humanos. Realizou-se, 
assim, a Conferência Nacional de Recursos Humanos para a Saúde, que foi um momento político importante na adoção de novas estratégias de desenvolvimento de recursos humanos. Nessa conferência apontou-se a necessidade de revisão da forma de preparação e capacitação dos profissionais de saúde, para que se pudesse propiciar a eles uma formação mais adequada às necessidades de saúde da população. Além disso, esses profissionais deveriam ser alvo de uma política que valorizasse seu trabalho e que permitisse sua ascensão profissional, sua dedicação ao serviço público e sua integração à equipe. Quanto ao médico-sanitarista, nenhum papel específico na condução e implementação das políticas de saúde lhe foi atribuído.

O projeto de recuperação do setor público de saúde, sua reformulação e o resgate de suas atribuições, passava necessariamente pela recuperação de seus profissionais, de seu papel nas instituições, de seu lugar dentro da equipe. A criação de um Sistema Único de Saúde universal, equânime, integral, descentralizado e hierarquizado, capaz de dar respostas técnico/operacionais às necessidades de resolutividade e eficiência dos serviços, impôs a discussão acerca da gerência do sistema. Fazia-se necessária uma nova prática gerencial, integrada a esse novo sistema de saúde.

Nesse cenário situa-se o médico-sanitarista, exercendo uma ocupação que historicamente perdeu prestígio, poder e reconhecimento social. Perda essa advinda do lugar a que foram relegadas as questões relativas à saúde coletiva no país. Tais questões foram tratadas de modo diferenciado e instável pelo Estado ao longo do tempo. Essa instabilidade, que caracteriza as instituições públicas responsáveis pela condução e implementação das políticas de saúde, fez com que essas instituições prestassem um serviço descoordenado, irracional, ineficiente e de baixa qualidade, revelando-se assim um descomprometimento da administração pública com seus fins, a res publica e o bem-estar do cidadão. Nessas instituições estão inseridos os sanitaristas (entre eles o médico), que se vêem muitas vezes à mercê dessa instabilidade.

O momento que se apresenta para a saúde coletiva vem marcado pela necessidade de reconstrução, de recuperação e retomada de sua importância na cena política e social do país. Vem marcado também pela necessidade de respostas, de resoluções, de afirmações. Para tanto, além da luta travada nos planos político, jurídico e institucional, a saúde coletiva defronta-se com a necessidade de instrumentalização e reorganização técnica.

O desafio da gerência configura uma nova face do médico-sanita- 
rista, a gerencial. Esta face evidencia a superação da antiga face generalista e a necessidade de instrumentalização para a solução de problemas em áreas fundamentais, as subáreas da saúde coletiva. A reformulação da prática e o redimensionamento do conhecimento apontam para o planejador, o epidemiólogo, o administrador. Aqui, os pares do médico-sanitarista não são os médicos, mas outros profissionais, que com ele se identificam pelo fato de exercerem a mesma ocupação - a de sanitarista. Nessa heterogênea coexistência ocupacional, a convivência entre diferentes interesses corporativos muitas vezes leva a conflitos na busca pelo reconhecimento profissional e legitimidade social. Reconhecimento e legitimidade já conferidos ao médico pelo fato de que ele pertence a uma comunidade que validou objetivamente sua competência (Starr, 1992).

O surgimento da face gerencial impõe uma reflexão a respeito das estratégias de formação de especialistas na área e das vias de formação de sanitaristas exclusivamente voltadas para a profissão médica, objetivando adequá-las a essa nova realidade. Uma das estratégias utilizadas tem sido a adoção de cursos para a formação de quadros técnicos em áreas específicas da saúde coletiva. Cursos que se multiplicam e se afirmam, numa demonstração da irreversibilidade do processo.

Quanto aos CBSP, eles têm passado por seminários periódicos de avaliação, de redefinição de perfil, de readequação à dinâmica política e institucional e às demandas advindas da divisão técnica do trabalho do profissional de saúde coletiva. Como já se disse anteriormente, também as Residências Médicas da área vêm passando por debates relativos a essas questões, acrescentando-se a elas discussões acerca de sua manutenção como formadoras apenas de especialistas médicos, da demanda do mercado por esses especialistas e, sobretudo, da não diferenciação dos mesmos pelo mercado de trabalho.

Como vimos, a saúde coletiva, por sua natureza social e pública, se afasta progressivamente dos interesses do corporativismo médico, e o médico-sanitarista, enquanto profissional, perde aos poucos a posição de direção técnica do processo, o domínio da especialidade e do mercado de trabalho. $\mathrm{O}$ avanço de tais acontecimentos transforma a saúde pública, de uma especialidade médica em uma ocupação multiprofissional, onde diversas categorias se completam, trocando experiências, conhecimentos e práticas.

Torna-se necessário, nesse momento, refletir acerca do que é ser sanitarista e identificar a especificidade do médico-sanitarista no universo dos profissionais de saúde coletiva. 
Ser sanitarista é atuar em uma área ampla, interdisciplinar e multiprofissional denominada saúde coletiva, cujo corpo de conhecimento não pertence a uma só categoria profissional, mas a várias. Uma área que oferece diversas possibilidades de formação de recursos humanos, tais como as Residências Médicas, os cursos de especialização e os cursos de pós-graduação.

A formação de sanitaristas se iniciou na década de 1920, com a criação do Curso de Higiene e Saúde Pública para formar médicos-sanitaristas. Estes, desde então, passaram por momentos históricos que lhes imprimiram diferentes faces, num movimento que aponta para uma superação paulatina do enfoque biologicista e para a incorporação de marcos conceituais emergentes da medicina preventiva e social. Observa-se, no processo de formação dos sanitaristas, que essa transformação de paradigmas caracterizou-se "pela busca de uma compreensão crítica dos processos de saúde-doença como fenômenos coletivos e da determinação social dos serviços de saúde articulada como uma proposta de intervenção sobre os processos de saúde-doença e as instituições do setor" (Labra, Stralen \& Scochi, 1988).

Muitas foram as definições e os papéis atribuídos ao sanitarista ao longo de sua história. Definições e papéis que foram se modificando nos diversos momentos políticos e institucionais pelos quais passou a área da saúde coletiva. O caráter multiprofissional do sanitarismo tornou-se evidente a partir da década de 1970, quando houve uma multiplicação e uma diversificação sem precedentes na formação de sanitaristas. Nessa época, a formação de recursos humanos para a área da saúde pública partia da concepção do sanitarista como um generalista, definindo-o como "um profissional capaz de identificar os determinantes do processo saúde-doença e da organização dos serviços de saúde, bem como de implementar estratégias de intervenção sobre a organização dos serviços e sobre práticas de saúde, com ênfase no compromisso político" (Labra, Stralen \& Scochi, 1988). Contudo, as expectativas em relação a esse profissional modificaram-se, superando o momento em que o sanitarista deveria pertencer a uma massa crítica com perfil de generalista em saúde pública. Como resultado da divisão técnica do trabalho, o novo perfil concebido para o sanitarista passou a ser o de um profissional apto a solucionar problemas de áreas específicas da saúde coletiva.

Durante todo esse processo esteve presente a figura do médico, um profissional que, pela legitimidade e autoridade a ele historicamente conferidas, teve sempre um papel de destaque na atividade do sanitarismo. 
Tendo sido o primeiro profissional a tornar-se sanitarista, devido às características de sua área de atuação, o médico foi paulatinamente compartilhando com outras categorias profissionais o saber, a prática e o mercado de trabalho da área. Isso faz com que o médico-sanitarista não possua, como os outros especialistas médicos, um corpo esotérico de conhecimento, um território exclusivo e uma sociedade de caráter nacional que o regule, aglutine e controle. Ele é um profissional híbrido, estranho aos interesses corporativos, sem identidade com seus pares.

A criação das Residências em medicina preventiva e social pode ser interpretada como uma tentativa de assegurar para a categoria médica o poder e o saber da área da saúde coletiva, para com isso reservar um mercado de trabalho que seria exclusivamente médico, como o das demais especialidades médicas. Mas, nesse caso, tal realidade não se conformou. Por isso, a discussão acerca da multiprofissionalidade das RMPS há muito vem sendo travada, e em alguns programas outros profissionais já se fazem presentes.

Mais do que multiprofissionais, as Residências em saúde coletiva perderam seus laços paradigmáticos com a medicina, escapando do poder e do controle da corporação. Esta, pur mais organizada e poderosa que seja, não conseguiu manter a saúde coletiva sob seu domínio. Se só aos médicos é permitido o exercício da medicina, uma medicina científica, nem só aos médicos-sanitaristas é permitido o exercício da atividade sanitária, uma atividade social, pública.

A medicina científica utiliza-se de seu paradigma para expurgar de seu interior tudo o que ela não considera científico. Isso, no entanto, não acontece sem que antes a suposta anomalia seja por ela apropriada e testada. Portanto, há que se supor algum tipo de reação da corporação médica a essa realidade aparentemente irreversível.

Há que se pensar também sobre a tendência que vem sendo verificada nas RMPS de um progressivo esvaziamento, de uma baixa demanda, concomitante a uma maior procura por outras especialidades. A saída do profissional médico dessa área de atuação irá sem dúvida produzir efeitos no saber, na prática e no próprio lugar ocupado pela saúde coletiva em nossa sociedade.

Concluindo, todas essas mudanças conduzem a questionamentos e dúvidas sobre as perspectivas do médico-sanitarista e sobre a própria existência futura dessa especialidade. A metamorfose pela qual passou o médico-sanitarista ao longo de sua história conferiu-lhe diversas faces, sendo a gerencial a sua face contemporânea. Contudo, o lugar secundário 
a que foram relegadas as questões sociais, entre elas a saúde, conduziu, nos dias de hoje, a um grave quadro sanitário. Um quadro bem semelhante ao que ocorreu no início deste século, constatando-se o retorno, em proporções epidêmicas, de doenças consideradas extintas. Num momento em que se discute avanços tecnológicos, modernidade, esse quadro faz pensar num retorno à face campanhista do sanitarista do início do século, na volta do mata-mosquitos, no pouco que se conquistou em termos de cidadania e no muito que ainda há por conquistar. Às indagações suscitadas pelo que se discutiu neste texto não se pode responder agora, mas certamente seus desdobramentos repercutirão de maneira decisiva sobre a saúde coletiva. Repercutirão também sobre os profissionais que nela atuam, e assim configurar-se-á, quem sabe, uma nova face do médico-sanitarista.

\section{Bibliografia}

AROUCA, A. S. da S. O Dilema Preventivista. Contribuição para a compreensão e crítica da Medicina Preventiva. Tese de doutorado em Medicina Preventiva e Social, Faculdade de Ciências Médicas, Universidade Estadual de Campinas, Campinas, 1975, 261 p.

BELISÁRIO, S. A. - Médico-Sanitarista: As muitas faces de uma ocupação. Dissertação de Mestrado, Escola Nacional de Saúde Pública, Fiocruz, RJ, 1993.

BRASIL. Ministério da Saúde. Conferência Nacional de Recursos Humanos para a Saúde. Relatório Final. Brasília, 1986.

BUSS, P. M. A Experiência do Programa de Apoio às Residências em Medicina Social, Medicina Preventiva e Saúde Pública (PAR-MS/MP/SP). Ensino de Saúde Pública, Medicina Preventiva e Social no Brasil. Rio de Janeiro, Abrasco/Nutes/Clates/Ensp, v. 1, 1982, p. 53-67.

DONNANGELO, M. C. F. 1975. Medicina e Sociedade: o médico e seu mercado de trabalho. São Paulo, Pioneira. 1975, 174 p.

DONNANGELO, M. C. F. \& PEREIRA, L. Saúde e Sociedade. 2a. ed., São Paulo, Duas Cidades, 1979, 124 p.

DUSSAULT, G. A. A Gestão dos Serviços Públicos de Saúde: características e exigências. Revista de Administração Pública. Rio de Janeiro, v. 26, nº 2 , 1992, p. 8-19.

ESCOREL, S. Reviravolta da Saúde: origem e articulação do movimento sanitário. Dissertação de Mestrado em Saúde Pública, Rio de Janeiro, Escola Nacional de Saúde Pública, Fiocruz, 2 v, 1987. 
FAVARET FILHO, P. \& OLIVEIRA, P. J. de. A Universalização Excludente: reflexões sobre as tendências do sistema de saúde. Dados - Revista de Ciências Sociais, Rio de Janeiro, v. 33, n² 2, 1990, p. 257-283.

FRIEDSON, E. The Reorganization of the Medical Profession. Medical Care Review. Spring, 1985, p. 11-35.

FUNDAÇÃO DO DESENVOLVIMENTO ADMINISTRATIVO. Requisitos Minimos de um Programa de Residência Médica: competências em Medicina Preventiva e Social. Documentos de trabalho n ${ }^{\circ}$ 63. São Paulo, 1992, 41 p. HERRIES-JENKINS, G. Professionals in Organizations. (s. n. t).

LABRA, M. E. O Movimento Sanitarista nos Anos 20: da conexão sanitária internacional à especialização em saúde pública no Brasil. Dissertação de Mestrado em Administração Pública. Rio de Janeiro, Escola Brasileira de Administração Pública, Fundação Getúlio Vargas, 1985, 410p.

LABRA, M. E, STRALEN, C. J. van \& SCOCHI, M. J. A Especialização em Saúde Pública no Brasil no Período 1982-1986. Estudos de Saúde Coletiva. Rio de Janeiro, Abrasco, v. 5, 1988, p. 47-96.

LUZ, M. T. As Instituições Médicas no Brasil: instituição e estratégia de hegemonia. $3^{\text {a }}$ ed., Rio de Janeiro, 1986, Graal, 295 p.

MARINHO, M. J. M. da C. Profissionalização e Credenciamento: a política das profissões. Coleção Albano Franco, Rio de Janeiro, Senai, 1986, 113 p.

MARX, K. Cooperação. In: Marx, K. O Capital: crítica da economia política. $4^{a}$ ed., Rio de Janeiro, Civilização Brasileira, v. 1, cap. XI, 1968, p. 370385 .

MENDES, E. V. A Evolução Histórica da Prática Médica: suas implicaçōes no ensino, na pesquisa e na tecnologia médicas. Belo Horizonte, PUC-MG/Finep, 1984, $124 \mathrm{p}$.

MORAES, L. F. R. Cultura organizacional: implicações para fusão e aquisição de empresas. Análise e Conjuntura. Belo Horizonte, v. 1, nº 3, 1986, p. 107-127.

NUNES, E. D. A Medicina Social no Brasil, um Estudo de sua Trajetória. Estudos de Saúde Coletiva. Rio de Janeiro, Abrasco, v. 5, 1988, p. 97-111.

PAIM, J. S. Medicina Preventiva e Social no Brasil. In: Paim, J. S. Saúde, Crises e Reformas. Salvador, Centro Editorial e Didático da UFBa, 1986, p. 29-41.

STARR, P. The Social Transformation of American Medicin. U. S. A.: Basic Books, 1992.

TEIXEIRA, S. M. F. O Dilema da Reforma Sanitária. In: Berlinger, G. , Teixeira, S. M. F. \& Campos, G. W. Reforma Sanitária na Itália e no Brasil. São Paulo, Hucitec/Cebes, 1988, p. 195-207.

(org.) Antecedentes da Reforma Sanitária. Textos de Apoio. Rio de Janeiro, Pec/Ensp, 1988. 
UCHOA, H. W. \& PAIM, E. R. A Experiência da ENSP com a Descentralização do Curso de Saúde Pública. Ensino da Saúde Pública, Medicina Preventiva e Social no Brasil. Rio de Janeiro, Abrasco/ Nutes/Clates/Ensp, v. 1., 1982, p. 53-67.

WILENSKY, H. L. The Profissionalization of Everyone. In: Grunsky, O. \& George, M. (eds.). The Sociology of Organization: Basic Studies. New York, The Free Press, 1970, p. 483-501. 